\title{
A REPRESENTAÇÃO DO OLHAR DA CRIANÇA SOBRE A INVESTIGAÇÃO
}

\author{
Mariana Menegat Schuck ${ }^{1}$ \\ Jacqueline Silva da Silva ${ }^{2}$
}

Resumo: $\mathrm{O}$ presente estudo decorre de um projeto de pesquisa intitulado "O Princípio da Investigação e a Pedagogia Empreendedora”, desenvolvido na Universidade do Vale do Taquari Univates. A pesquisa teve o objetivo de aprimorar a prática investigativa nas crianças da Educação Infantil e dos Anos Iniciais por meio das representaçôes dos seus olhares sobre a investigação, para que, assim, pudessem perceber a ciência como uma ação procedente da investigação. Presente no nosso cotidiano, a investigação se revela em pequenos atos, tais como a observação de uma borboleta (SILVA, 2011). O estudo seguiu uma abordagem qualitativa, que tem seu foco de estudo nos sujeitos e em toda sua complexidade, sendo que o investigador preocupa-se com o sentido que o participante dá à sua própria vida (BOGDAN; BIKLEN, 1994). O locus da pesquisa foram duas escolas da rede pública do município de Lajeado/RS/BRA, sendo uma da Educação Infantil e a outra do Ensino Fundamental. Como instrumentos de pesquisa foram utilizados registros fotográficos, desenhos e escrita criativa. Observou-se que o trabalho por investigação junto às crianças foi muito relevante, levando em consideração seus interesses e necessidades. Além disso, percebeu-se também que foi fundamental darmos vez e voz às crianças e o quanto a escuta atenta do professor é indispensável para sabermos o que elas têm a nos dizer a respeito da vida.

Palavras-chave: Investigação. Educação Infantil. Ensino Fundamental. Prática Investigativa.

\section{REPRESENTATION OF THE CHILD'S LOOK ON RESEARCH}

\begin{abstract}
This present study is the result of a research project entitled "The Research Principle and an Entrepreneurial Pedagogy", developed at the University of Taquari Valley - Univates. The research aimed to investigate the practices of early childhood education so that one can perceive science as a procedural action of the investigation. The research is present in our daily lives, in
\end{abstract}

1 Graduanda de Arquitetura e Urbanismo e Bolsista de Iniciação Científica da Universidade do Vale do Taquari - Univates. Email: mmschuck@universo.univates.br

2 Doutora em Educação - UFRGS, docente do curso de Pedagogia e do Programa de PósGraduação Mestrado em Ensino da Universidade do Vale do Taquari - Univates. E-mail: jacqueh@univates.br 
small acts, as a comment of a butterfly (SILVA, 2011). The study followed a qualitative approach, which has its focus of study on the subjects and all its complexity, and the researcher is concerned with the meaning that the participant gives his own life (BOGDAN; BIKLEN, 1994). The locus of the research was two public schools that are located in the municipality of Lajeado/RS/BRA, one of the School of Early Childhood Education and the other Elementary School. The research tools were used pictures, drawings, and creative phrases. It was observed that the research work with the children was very relevant, taking into account their interests and needs. Besides, it was also realized that it was essential to give the children voice and how much the attentive listening of the teacher is indispensable to know what the children have to say about life.

Keywords: Research. Early Childhood Education. Elementary School. Investigative Practice.

\section{INTRODUÇÃO}

O presente trabalho decorre do projeto intitulado "A representação do olhar da criança sobre a investigação", que teve apoio da Fundação de Amparo à Pesquisa do Estado do Rio Grande do Sul - FAPERGS. O objetivo do estudo foi compreender o modo como as crianças interpretam a investigação e como esta está presente no cotidiano delas. Neste trabalho, caracteriza-se como investigação as ações de observar, experimentar, refletir e relatar sobre o que é vivenciado no cotidiano.

O ser humano possui características que definem a investigação ainda na infância, tais como a curiosidade, a observação e, principalmente, a experimentação dos sentidos, dentre outras. Ao longo do crescimento, a criança vai adquirindo experiências, e com isso, impulsiona o seu desenvolvimento. É nessa fase que ela se questiona sobre o mundo e sobre perguntas que ainda não possuem uma resposta única ou definitiva, como, por exemplo, para onde vamos quando morremos? A criança, pode encontrar resposta(s) para esses questionamentos por meio dos familiares, do senso comum, em crenças e tradições, e outros mais, uma vez que as concepções dela a respeito das coisas que a rodeia, parte geralmente das experiências que ela mesma vivencia.

Por isso, a presente pesquisa teve a intenção de oportunizar às crianças momentos de investigação e de reflexão a respeito de situações que emergiam no cotidiano delas. Um exemplo disso, foi a discussão sobre a questão se elas poderiam ser consideradas cientistas, já que estas buscavam respostas aos seus questionamentos por meio da investigação.

Ao ingressarem na escola, as crianças estão suscetíveis a muitas aprendizagens. É por meio de situações de aprendizagem e experiências propostas pelo professor que vai se dando o desenvolvimento da criança. Sendo assim, a figura do professor passa a exercer um papel fundamental na formação das mesmas, pois ao inserir o princípio da investigação em suas práticas pedagógicas, o professor dá a oportunidade para que elas despertem o interesse para irem em busca de respostas das suas indagações. Desta forma, o professor está contribuindo para a formação de sujeitos autônomos, capazes de encontrarem soluções para os desafios que se deparam cotidianamente. 
Assim, percebe-se a importância do trabalho com a investigação em sala de aula, pois além de possibilitar que a criança seja protagonista de suas próprias aprendizagens, esse princípio permite que as crianças tenham contato com um outro ambiente. Nesse sentido, é possível elas realizarem observações, experimentações e reflexões sobre o interesse manifestado, bem como, oferecer a elas a oportunidade de explorarem os diversos materiais que são disponibilizados para a realização da pesquisa.

A seguir trazemos uma breve conceituação sobre a importância da investigação para o ensino e o papel do professor nesse contexto. Na sequência é feita uma análise e discussão dos dados obtidos junto às duas escolas da rede municipal de ensino, localizadas em Lajeado/RS/BRA. Destacamos a representação do olhar das crianças sobre a investigação, a partir dos desenhos criados por elas e das escritas criativas realizadas durante a pesquisa.

\section{IMPORTÂNCIA DA INVESTIGAÇÃO PARA O ENSINO}

Nos últimos anos, temos observado uma crescente preocupação por parte dos professores, em propiciar momentos em sala de aula que estimulem as crianças a serem protagonistas das ações que realizam, sendo a investigação um princípio apropriado a essa prática pedagógica, conforme Silva (2011, p.24) caracteriza a criança protagonista como alguém que é "dotada de extraordinária capacidade de aprendizagem e de mudança, de múltiplos recursos afetivos, relacionais, sensoriais, intelectuais, que se explicitam numa troca incessante com o contexto cultural e social".

Desta forma, é de extrema importância a participação da criança no desenvolvimento da sua aprendizagem, já que a experimentação a leva a aprender sobre o mundo e como este funciona (SILVA, 2011). Cabe ao professor propiciar situações de aprendizagem que despertem nas crianças o interesse em investigar o mundo, levando em consideração seus próprios interesses, instigando-as à curiosidade e contribuindo para a sua formação. Assim, o professor realiza o desenvolvimento dos conteúdos, contando com um planejamento voltado "para e com as crianças" (SCHNEIDER, 2015, p. 17).

Destacamos que o ensino por investigação caracteriza-se por ser uma ação diária, que busca possibilidades para a resolução de problemas do cotidiano e que também se destaca por ser um dos doze princípios do projeto pedagógico das escolas infantis de Reggio Emilia/Itália, que promove o desenvolvimento de um planejamento dentro de uma abordagem emergente (SILVA, 2011).

O método de ensino por investigação. conforme definido por Lorenzon (2018, p. 31) segue os seguintes passos: "elaboração de questionamentos, formulação de hipóteses, construção dos argumentos e comunicação dos achados". Não há uma ordem predeterminada a ser seguida, nem um tempo pré-determinado para a realização das situações de aprendizagem. Cabe ao professor exercer a função de otimizador do tempo. 
Desse modo, o papel do educador é essencial, pois de acordo com Ferraz e Sasseron (2017, p. 4) "O ensino por investigação só será de fato investigativo se o professor promover condições para que ele ocorra". Além disso, é necessário que o professor organize o planejamento de um roteiro que tenha objetivos claros, levando em consideração os "[...] espaços que serão ocupados, nos materiais que serão disponibilizados às crianças, nas possíveis descontinuidades do projeto e, sobretudo, nas intencionalidades de cada etapa pensada" (SILVA, BEUREN, LORENZON, 2016, p. 16).

Com o intuito de instigar a curiosidade e desenvolver a criatividade da criança, o professor pode estimulá-la por meio do levantamento de hipóteses e da busca por respostas às suas indagações. Vale destacar que o ambiente e os recursos utilizados também podem contribuir no processo de aprendizagem, pois motivam a criança a querer saber mais e ir em busca das respostas de suas perguntas.

\section{METODOLOGIA}

A investigação seguiu a abordagem qualitativa de pesquisa. Esta caracteriza-se por ter seu foco nos sujeitos e em toda sua complexidade, sendo que o investigador preocupa-se com o sentido que o participante dá à sua própria vida (BOGDAN; BIKLEN, 1994).

Conforme já descrito anteriormente, o contexto deste estudo foram duas escolas, uma de Educação Infantil e outra de Ensino Fundamental da rede pública de ensino, situadas no município de Lajeado/RS/BRA. Na escola de Educação Infantil o trabalho se efetivou com uma turma composta por 23 crianças com idades entre 5 e 6 anos, e na escola de Ensino Fundamental, com uma turma do segundo ano, composta por 22 crianças com idades entre 7 e 8 anos. Destacase que, tanto os professores quanto os responsáveis pelas crianças, deram seus consentimentos, através da leitura e assinatura do Termo de Consentimento Livre e Esclarecido (TCLE).

Para a coleta de dados, foi utilizado um plano de trabalho previamente elaborado pelas pesquisadoras, o qual conteve cinco situações de aprendizagem, cada uma com seu objetivo e desenvolvimento estruturado. Para tanto, as professoras das duas escolas investigadas foram contatadas por meio do e-mail pessoal. Este, disponibilizado pelas redes de ensino, a fim de agendar os dias e horários para a aplicação do plano de atividades nas turmas. Assim, as situações de aprendizagem foram desenvolvidas duas vezes por semana em cada turma, em dias alternados, com duração de 45 minutos cada encontro.

As atividades foram divididas em situações de aprendizagem, entretanto, no primeiro momento realizou-se uma observação de uma aula, na qual as pesquisadoras analisaram o cotidiano das crianças em relação à investigação, e seu modo de interagir no contexto escolar. Em relação às situações de aprendizagem, estas foram divididas da seguinte forma: a $1^{a}$ situação teve por objetivo a identificação da investigação pelas crianças através de imagens que foram apresentadas a elas no Datashow. Estas imagens eram compostas de fotos de pessoas de jaleco branco, 
que estavam num laboratório e de outras pessoas realizando ações do cotidiano, como alguém observando uma flor em um jardim. $\mathrm{Na} 2^{a}$ situação de aprendizagem, as crianças foram convidadas a irem até o pátio da escola para fotografarem o que mais chamou a sua atenção nesse espaço, sendo que cada uma poderia fazer o registro de até cinco imagens. $\mathrm{Na} 3^{a}$ situação, ocorreu a discussão sobre os registros fotográficos e foi solicitado a cada criança que escolhesse apenas uma das cinco imagens registradas e que representasse melhor aquilo que havia observado, para posteriormente expor essas imagens. $\mathrm{Na} 4^{a}$ situação as crianças foram desafiadas a representarem o que descobriram sobre as atividades realizadas, utilizando a escrita criativa e os desenhos para isso. Destacamos que as crianças da Educação Infantil fizeram uso dos desenhos e as do Ensino Fundamental, da escrita criativa. Por fim, na $5^{a}$ situação de aprendizagem, as turmas foram convidadas a apresentarem as suas produções e a expressarem o que haviam aprendido sobre o ato de investigar.

Para a análise dos dados, utilizou-se uma aproximação com a técnica da Análise de Conteúdo, proposta por Bardin (2012). Para o autor, essa técnica envolve três etapas: a pré-análise do material, com o intuito de organizá-lo, relacionando-o com a questão da pesquisa; a exploração do material, sendo esta a fase em que a análise torna-se mais detalhada, ocorrendo o desmembramento por categorias, seguido do reagrupamento por unidades de sentido e o tratamento dos resultados obtidos e a interpretação, levando em conta o objetivo inicial.

\section{ANÁLISE E DISCUSSÃO DOS DADOS}

\section{Situaçöes de Aprendizagem}

Para a realização da pesquisa, seguiu-se um Plano de Trabalho, composto por cinco situações de aprendizagem. Nas quais, em cada uma realizou-se atividades diferenciadas que tinham o foco na investigação. Cada situação de aprendizagem contou em 45 minutos de encontro, durante duas vezes por semana em cada escola.

Em um primeiro momento, ocorreu uma observação das bolsistas em relação às turmas, possibilitando uma análise dos alunos, compreendendo a postura destes em relação à turma. Além, compreendeu-se o funcionamento do cotidiano dessas crianças, procurando notar o modo como a investigação está presente, e a maneira que os professores a trabalham.

Na primeira situação de aprendizagem, realizou-se uma roda de conversa, na qual as crianças sentaram-se em círculo, no chão. Com isso, iniciou-se a seção de imagens projetadas no Datashow. No primeiro momento dessa situação de aprendizagem, foram apresentadas imagens que retratavam a ideia preconcebida de quem seriam os cientistas, como sendo pessoas que trabalham em laboratórios, usam jalecos e realizam experimentos e logo, foram apresentadas imagens de pessoas em situações da vida cotidiana. No segundo momento, a partir das visualizações, foram realizados os seguintes questionamentos às crianças: "O que é um cientista?", "O que ele faz?", "Onde eles trabalham?”, "Todos nós podemos ser cientistas?”. De 
imediato, foram respondendo: "Ele é um cientista louco!"; "O cientista é o cara que faz. poção"; "Os cientistas olham insetos, porém enxergavam esses insetos - 'coisas bem pequeninhas' - grandes"; "O cientista trabalha com robôs"; "Em laboratório de robô e com experimentos cientificos"; "Na Univates"; "Eu não posso ser cientista"; "Nem todo mundo"; "Acho que sim".

Já na segunda situação de aprendizagem, ocorreu uma produção de fotografias, para que os alunos registrassem o que lhes chamou mais atenção a respeito da investigação. Deste modo, foram disponibilizadas câmeras fotográficas para as crianças e celulares, para que as mesmas fotografassem cenas que lhes permitissem investigar e que ao mesmo tempo pudessem expressar o que pensavam ser a investigação. As perguntas norteadoras foram: "Como percebo?", "O que chama a minha atenção?", "Já havia percebido antes?" Notou-se que o foco das crianças foi a investigação de insetos e plantas, sendo que, geralmente eles analisavam características como cor, tamanho e textura ou faziam perguntas do por que daquele inseto ser daquela cor ou formato. Já nas plantas, as crianças geralmente questionavam sobre especificidades de cada planta, como por exemplo a fruta da planta, que fica caída no chão, de que parte da árvore ela vem?

$\mathrm{Na}$ terceira situação de aprendizagem projetou-se as fotografias registradas pelas crianças no Datashow. Enquanto as imagens eram passadas, cada criança deveria explicar sobre o por que havia registrado a foto, gerando uma roda de conversa. Assim, as crianças puderam aprimorar seus olhares sobre a investigação, ouvindo os colegas sobre o que estes haviam investigado, e percebendo características que ainda não tinham percebido, ou seja, refletindo sobre as investigações.

A quarta situação de aprendizagem teve por objetivo a representação do olhar das crianças sobre a investigação através de desenhos e da escrita criativa. Assim, foram utilizadas duas propostas como forma de obtenção de informações: o desenho, realizado pelas crianças da Educação Infantil e a escrita criativa, pelas crianças do segundo ano do Ensino Fundamental. Para a criação dos desenhos foram utilizados lápis colorido, canetas coloridas e folhas tamanho A3. E para a escrita criativa também foram utilizados lápis e canetas coloridas, porém o tamanho da folha foi em A4.

\section{Os desenhos}

A partir das imagens fotografadas, decorrentes da atividade realizada na segunda situação de aprendizagem, as crianças foram desafiadas a criarem um desenho como forma de representação das suas observações.

Diante da empolgação das crianças de usufruírem outro espaço da escola para realizarem o desafio proposto, diferente da sala de aula, nos fez perceber também, a importância de envolvermos outros espaços para que aprimorem as suas experiências, conforme defende Horn (2004, p. 18), "Partindo do entendimento de que as crianças também aprendem na interação com seus pares, é fundamental o planejamento de um espaço que dê conta dessa premissa, permitindo que, ao conviver com grupos diversos, a criança assuma diferentes papéis e aprenda a se conhecer melhor". 
Em virtude do espaço para a construção do desenho ser um local aberto, o que mais destacou-se nas produções das crianças foram os insetos. Além disso, a imagem da lupa, que foi projetada por meio dos slides, na primeira situação de aprendizagem, também apareceu nos desenhos das crianças, mesmo ela não sendo utilizada na realização dessa atividade. Dentre essas produções, observa-se abaixo o desenho de uma das crianças.

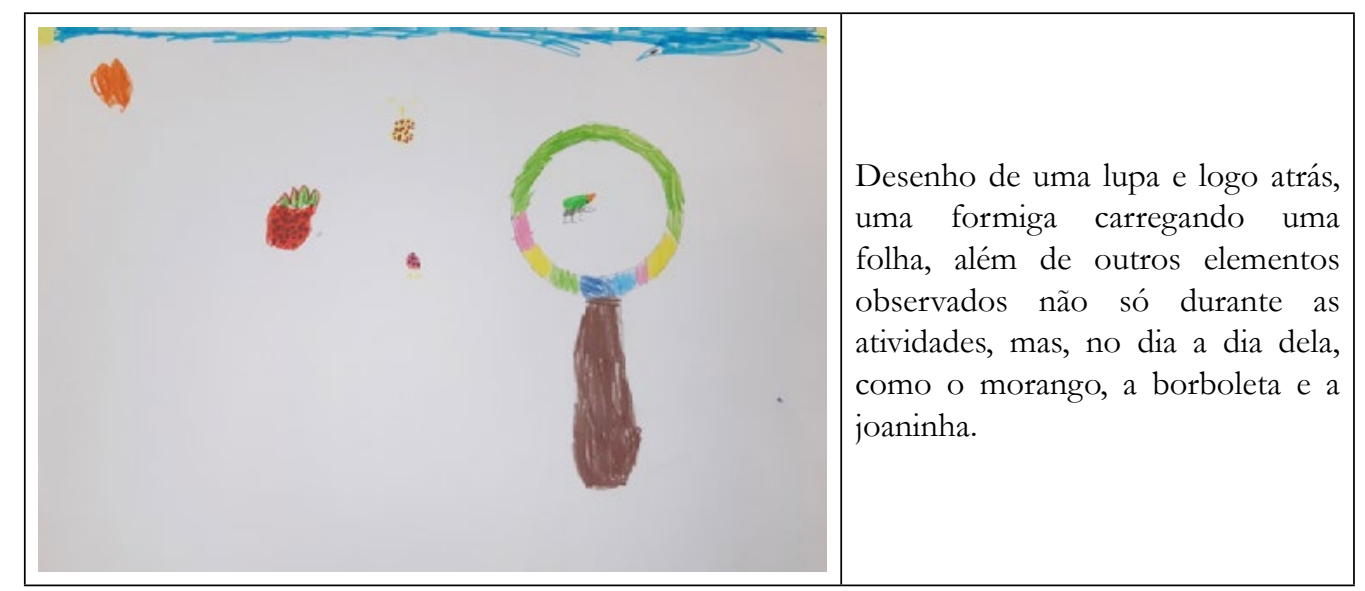

FONTE: Aluna Manuela.

A criação que vem a seguir chamou a atenção. Pois além do aluno Arthur desenhar a natureza, apresentando as árvores, as nuvens, o sol e os elementos do pátio, como a casinha de brincar, ele também desenhou o entorno da escola, como por exemplo a igreja que fica ao lado e os carros estacionados. Ele ainda apresentou detalhes, como uma borboleta voando e algumas crianças que no pátio, no momento da criação, encontravam-se brincando. Assim, percebe-se a relação da imagem criada pela criança ao seu pensamento, aos seus conhecimentos, as suas experiências de vida e o modo como percebe o mundo que a rodeia. Nesse sentido, a investigação é o olhar "atento e sensível à realidade de múltiplos ângulos e olhares que podem ser dirigidos a ela, selecionados, registrados, lidos e reinterpretados" (LOPES, 2009, p.77). 


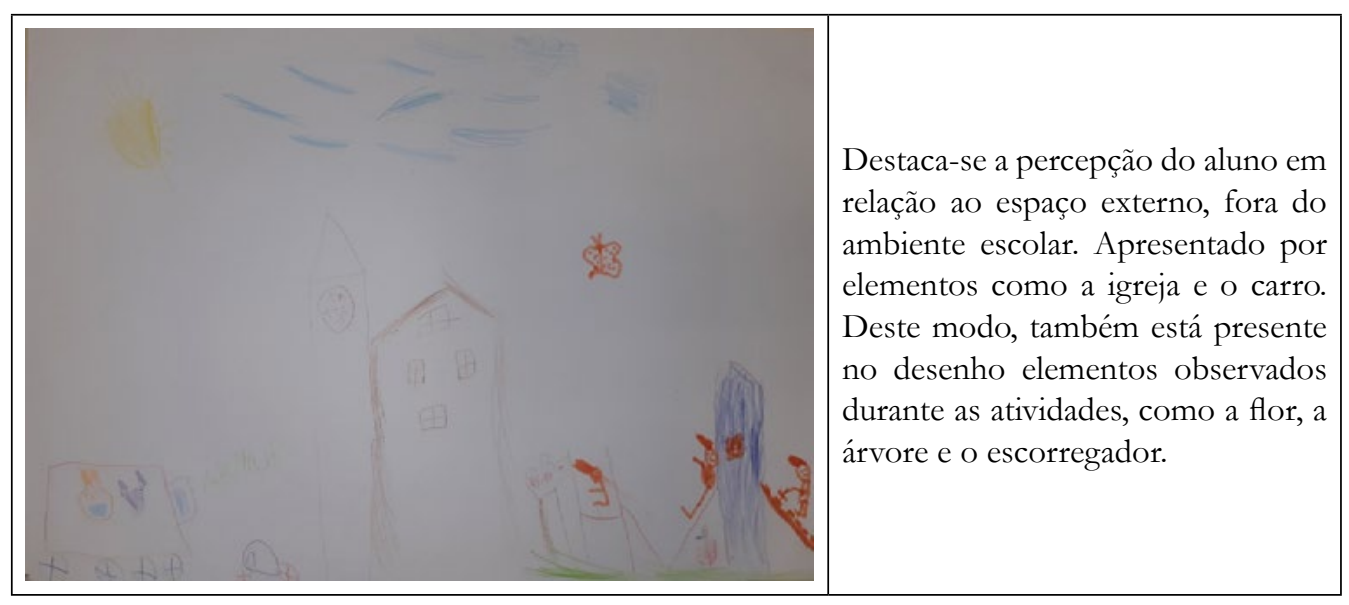

FONTE: Aluno Arthur.

Grande parte das crianças representaram em suas criações elementos observados durante a situação de aprendizagem em que realizaram os registros fotográficos. Os elementos mais presentes em seus desenhos foram: árvores, sol, nuvens, flores, borboletas, pedras, formigas, lupas, pessoas e pássaros. Porém, somente uma dessas criações apresentou a natureza de um modo diferente. Conforme a criança relatou, "aquilo que têm embaixo da terra e a gente só vê se revirá ela. As minhocas".

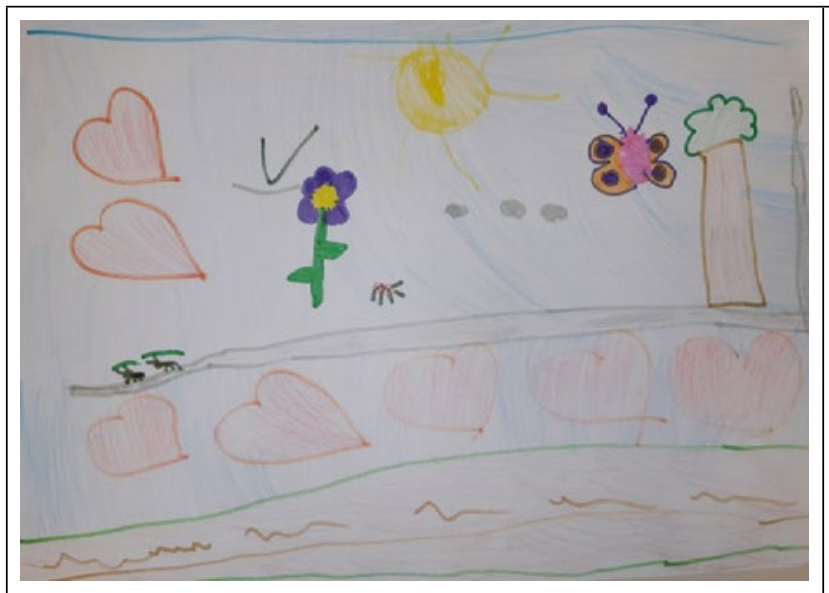

Desenho que mostra uma experiência e investigação de espacialidade da criança. Com as minhocas embaixo da terra, e elementos observados durante as atividades em cima, como as formigas, a flor, a árvore, a borboleta e as pedras.

FONTE: Aluna Alexia.

O desenho apresenta uma noção de espacialidade, por meio da noção que a criança teve de colocar as formigas acima, em uma laje e as minhocas abaixo, na terra. Dessa forma, percebe-se que a criança utilizou conhecimentos prévios para essa criação que podem ter sido trabalhados em projetos investigativos proporcionados pela escola de Educação Infantil, como também de experiências já vividas em outros momentos, mesmo fora da escola. 


\section{Escrita Criativa}

A atividade da escrita criativa foi desenvolvida com os alunos do $2^{\circ}$ ano do Ensino Fundamental e caracterizou-se como uma escrita informal, com o objetivo da criança dissertar sobre as experiências vividas de modo que expressassem a criatividade. Para Barbosa (2018, p. 11), "a escrita criativa deve ser vivida, criada, inventada, ludibriada e sensibilizada".

E assim, a partir das imagens fotografadas, decorrentes da atividade realizada na segunda situação de aprendizagem, as crianças construíram seus textos onde puderam também adicionar na escrita, os desenhos que foram criados a partir da leitura visual das fotografias tiradas. Nesse desafio proposto às crianças, nos foi possível verificar o quanto a imagem possui significado para elas, uma vez que através dela relembraram acontecimentos que lhes permitiram a escrita do texto. Nesse sentido, Lopes (2009) corrobora argumentando que "a fotografia resgata na memória a experiência vivida, redimensionando-a a partir da observação e da análise desses registros, fragmentos da realidade".

Diante do exposto, constatamos o quanto foi importante o registro das experiências das crianças no decorrer da pesquisa, uma vez que "as fotografias não são tidas como confirmação de uma situação, mas como um ponto de partida para a reflexão" (LOPES, 2009, p.81). E, por meio desses registros, houve a possibilidade de conhecer o que as crianças aprenderam com o trabalho realizado e os resultados alcançados. Além disso, vale destacar que, por meio das produções, tanto as fotografias quanto os registros escritos, a criança resgata seu pensamento anterior e consegue questionar-se novamente, aprofundando as suas aprendizagens.

Assim, junto com as crianças, realizou-se uma atividade de escrita criativa, a partir da pergunta "O que é investigação?" Cada aluno escreveu sobre o que pensava ser investigado, levando em consideração as demais atividades realizadas durante o projeto. Para a realização desta atividade, foram utilizadas folhas de almaço e dos próprios materiais que as crianças usavam diariamente, como lápis de escrever e de colorir, canetinhas e canetas coloridas. Em vista dos materiais e do que havia sido desenvolvido nas situações de aprendizagem, as escritas criativas resultaram em textos com e sem desenhos. A maioria das crianças explicou sobre onde e o que se poderia pesquisar e que a investigação exige pensar, observar e registrar o que existe ao nosso redor.

A seguir, apresentamos algumas das escritas que envolveram características similares. A maioria das produções associavam características mais gerais do que havia sido investigado, como a cor, o tamanho e a textura de uma borboleta por exemplo. Nathan refere-se a essas características em sua escrita criativa. O aluno descreveu uma ruga (taturana), apresentando características gerais, tais como o tamanho. Também é possível perceber na escrita características mais específicas, tais como nem todas as rugas são iguais, o pelo e as suas cores. 


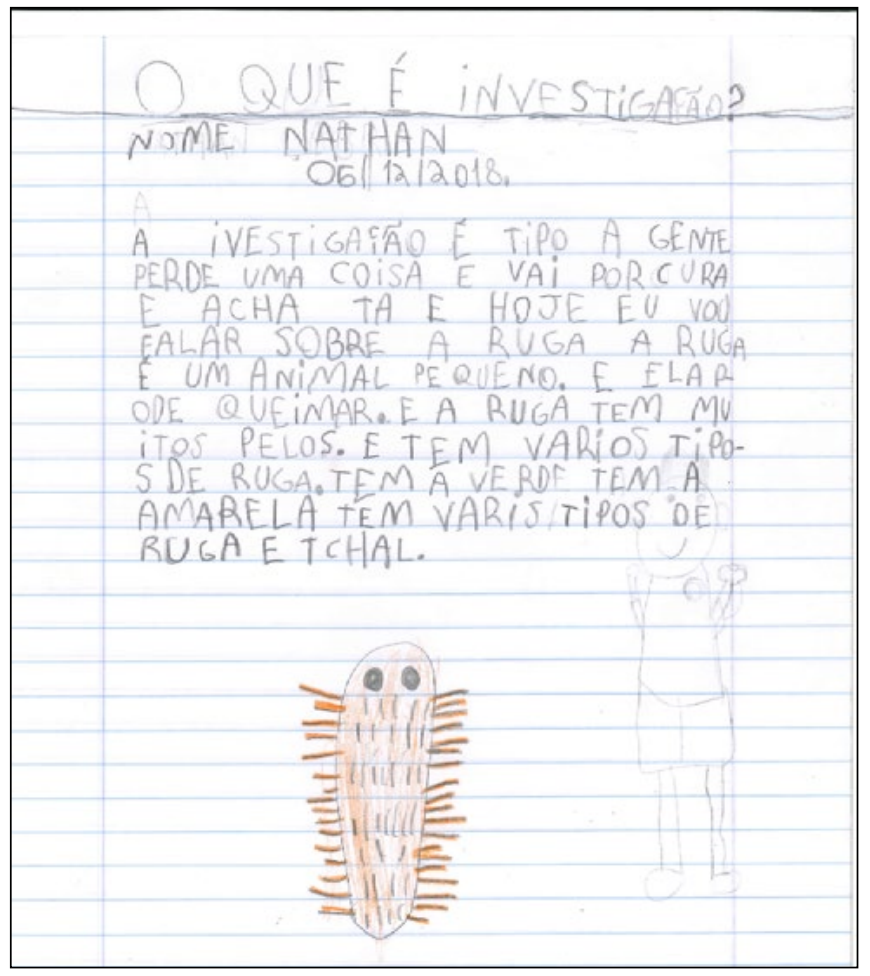

FONTE: Aluno Nathan.

Destacamos também que algumas crianças relacionaram descobertas da ciência com a investigação, como nesta escrita da aluna Giovana: "A investigação é uma coisa que podemos achar e nunca foram descobertas. Igual ao câncer, cientistas estão tentando descobrir". Também, relacionou fatos ocorridos no passado com presente, descrevendo a evolução do ser humano, unindo teorias científicas e religiosas: "Também a investigação far.parte do futuro, algumas pessoas acreditam que a gente era macacos e foram 'tirado' nosso pelo, e outros dizem que a gente nasceu de Adão e Eva”. 


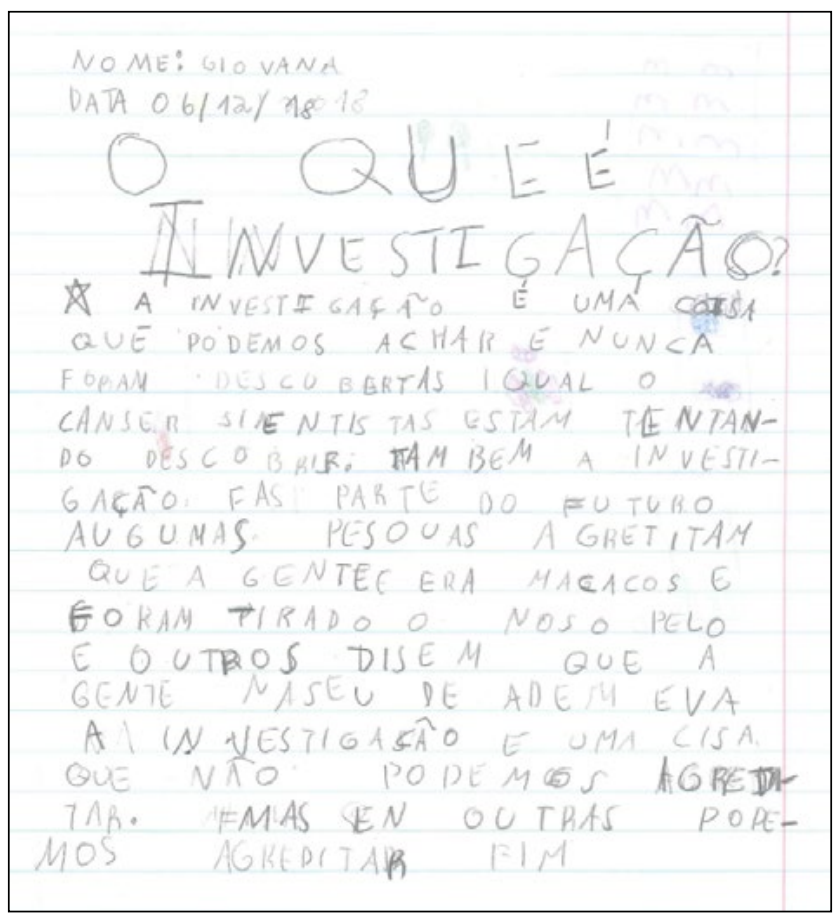

FONTE: Aluna Giovana.

A quinta situação de aprendizagem permitiu as crianças a reflexão sobre o que as mesmas haviam entendido e construído sobre o que seria a investigação, levando em consideração tudo o que havíamos desenvolvido com elas até aquele momento. Também permitiu às crianças que se descobrissem como investigadoras. Sentadas em círculo, foi proposta pelos pesquisadores uma roda de conversa com a seguinte questão: "O que eu descobri?" Segundo as crianças: "Se tu acha uma coisa interessante, tu pesquisa, e vai descobrir uma resposta pra responder o que é aquilo, se é pra se proteger, ..."; "Se pode pesquisar pela internet ou pela foto, olhando ela".

Compreendemos que a investigação trabalhada nas atividades levou as crianças a descobrir-se investigadoras, não somente investigando em seus cotidianos, mas procurando ferramentas que ajudem-as a encontrar respostas às suas indagações. Assim, a partir de experiências e observações realizadas no cotidiano dessas crianças, elas procuram respostas às suas indagações e questionam-se novamente, levando à reflexão, então, para organizar as ideias, as crianças relatam o que foi investigado, por meio da escrita ou da comunicação. Deste modo, a comunicação principalmente com os colegas, leva as crianças ao compartilhamento, adquirindo novas experiências.

\section{CONSIDERAÇÓES FINAIS}

Por meio deste trabalho foi possível observar que as crianças investigam o tempo todo e assim, através de ações de observação, experimentação e reflexão 
sobre o mundo ao seu redor, elas descobrem e entendem o que acontece no cotidiano. Pela experimentação, a criança desenvolve os sentidos, e com isso, inicia sua compreensão sobre o mundo, sobre o que os cerca. Portanto, esse método envolve tanto os sentidos, quanto a razão, o primeiro pela observação e experimentação, e a razão pela reflexão e o relato da investigação.

Deste modo, por meio desta pesquisa aprimorou-se a prática de investigação de acordo com os "olhares" de cada criança. Dessa forma, elas puderam compreender que a ciência é uma ação procedente da investigação e que eles também são cientistas. Autores como Silva, Beuren e Lorenzon (2016) mencionam sobre a semelhança entre a investigação com as crianças e a pesquisa científica: "enquanto na pesquisa científica essa preocupação é formal, na investigação com crianças, é uma preocupação informal, que objetiva principalmente a sua aprendizagem" (SILVA, BEUREN, LORENZON, 2016, p. 9).

Neste sentido, as ações oportunizadas "para e com as crianças" (SCHNEIDER, 2015, p. 17) durante cada situação de aprendizagem, afirmaram o quanto é importante darmos vez e voz a elas, levando em consideração seus interesses e necessidades. Em vista disso, precisamos considerar as ferramentas utilizadas, o ambiente e a escuta atenta do professor, que levam-no a desenvolver um planejamento voltado para as crianças, buscando escutá-las e auxiliando que elas sejam protagonistas de suas aprendizagens.

Deste modo, notou-se a importância do projeto na vida dessas crianças, pois a investigação leva estas a ter um olhar diferente sobre o mundo que as cerca. Assim, elas observam e prestam atenção nos detalhes, seja de insetos ou plantas, por esta ação de observar, elas começam a interpretar as coisas, se questionando, encontrando a resposta e perguntando-se novamente. Isso é o se aprofundar, mesmo que eles não possuem um entendimento ampliado (por causa da idade), todos esses passos citados acima, referentes à investigação, auxiliam e proporcionam o aprendizado das crianças.

Por meio dos desenhos e das escritas criativas foi possível entender o aprendizado das crianças sobre a investigação. Notamos como crianças investigam, o que investigam e o que é realmente do interesse delas, assim, constatamos a investigação de insetos e plantas como principais, os questionamentos referentes às características e as mesmas destacaram as ferramentas que podem ser utilizadas, como livros, celulares e até pela comunicação com outras pessoas. Em vista disso, o projeto proporcionou entendermos o olhar que a criança teve sobre a investigação e sobre o método utilizado, sendo que, gerou um resultado positivo de compreensão do que é a investigação, reconhecendo-se investigadores.

\section{REFERÊNCIAS}

BARBOSA, Poliana Wathier. Escrita Criativa e Autoral nos Anos Iniciais:

Evidenciando a Essencialidade de um Grafar Criativo. Lajeado/ RS, 2018.

BARDIN, Laurence. Análise de conteúdo. São Paulo: Edições 70, 2012. 
BOGDAN, Robert; BIKLEN, Sari. Investigação qualitativa em educação: uma introdução à teoria e aos métodos. Porto: Porto Editora, 1994.

FERRAZ, Arthur T.; SASSERON, Lúcia H. Espaço Interativo de Argumentação Colaborativa: condições criadas pelo professor para promover argumentação em aulas investigativas. Ensaio Pesquisa em Educação em Ciência . 19, Belo Horizonte, 2017. Disponível em: <http://www.scielo.br/scielo.php?script=sci_arttext\&pid=S198321172017000100215\&lng=pt\&nrm=iso > . Acesso em: 20 fev, 2019.

HORN, Maria da Graça Souza. Sabores, cores, sons, aromas: a organização dos espaços na educação infantil. Porto Alegre: Artmed, 2004.

KRAMER, Sonia; LEITE, Maria I.; LOPES, Ana E.; PORTO, Cristina L.; DESGRANGES, Flávio; NOGUEIRA, Letícia; CABRAL, Márcia; PEREIRA, Rita M.R.; SOUZA, Solange J. Infância e produção cultural. $8^{a}$ ed. São Paulo: Papirus, 2009, p. 75-107; p. 131-150.

LORENZON, Mateus. A espiral investigativa como uma estratégia de desenvolvimento da alfabetização científica nos anos iniciais do ensino fundamental. Dissertação (Mestrado). Universidade do Vale do Taquari, Programa de Pós-Graduação em Ensino, 2018.

SCHNEIDER, Mariângela C. O protagonismo infantil e as estratégias de ensino que o favorecem em uma turma de educação infantil - Dissertação (Mestrado). Centro Universitário Univates, Programa de Pós-Graduação Strictu Sensu, 2015.

SILVA, Jacqueline Silva da; BEUREN, Jéssica; LORENZON, Mateus. Investigar com crianças: subsídios para formação e trabalho docente. Lajeado: Univates, 2016.

SILVA, Jacqueline Silva da. O planejamento no enfoque emergente: uma experiência no $1^{\circ}$ ano do Ensino Fundamental de nove anos. Tese (Doutorado). Universidade Federal do Rio Grande do Sul, Programa de Pós-graduação em Educação, 2011. 